\title{
DISTINGUISHING CARTESIAN PRODUCTS OF COUNTABLE GRAPHS
}

\author{
EHSAN ESTAJI \\ Hakim Sabzevari University, Sabzevar, Iran \\ e-mail: ehsan.estaji@hsu.ac.ir \\ WILFRIED IMRICH \\ Montanuniversität Leoben, A-8700 Leoben, Austria \\ e-mail: imrich@unileoben.ac.at \\ Rafae Kalinowski, Monika Pilśniak ${ }^{1}$ \\ AGH University, Department of Discrete Mathematics \\ 30-059 Krakow, Poland \\ e-mail: kalinows,pilsniak@agh.edu.pl \\ AND \\ Thomas Tucker ${ }^{2}$ \\ Colgate University, Hamilton NY 13346, USA \\ e-mail: ttucker@colgate.edu
}

\begin{abstract}
The distinguishing number $\mathrm{D}(G)$ of a graph $G$ is the minimum number of colors needed to color the vertices of $G$ such that the coloring is preserved only by the trivial automorphism. In this paper we improve results about the distinguishing number of Cartesian products of finite and infinite graphs by removing restrictions to prime or relatively prime factors.

Keywords: vertex coloring, distinguishing number, automorphisms, infinite graphs, Cartesian and weak Cartesian product.

2010 Mathematics Subject Classification: 05C25, 05C15, 03E10.

\footnotetext{
${ }^{1}$ Rafał Kalinowski and Monika Pilśniak were partially supported by the Polish Ministry of Science and Higher Education.

${ }^{2}$ Thomas Tucker was supported by Grant 317689 from the Simons Foundation.
} 


\section{REFERENCES}

[1] M.O. Albertson, Distinguishing Cartesian powers of graphs, Electron. J. Combin. 12 (2005) \#N17.

[2] M.O. Albertson and K.L. Collins, Symmetry breaking in graphs, Electron. J. Combin. 3 (1996) \#R18.

[3] R. Hammack, W. Imrich and S. Klavžar, Handbook of Product Graphs (Second Edition), (Taylor \& Francis Group, 2011).

[4] W. Imrich, Automorphismen und das kartesische Produkt von Graphen, Österreich. Akad. Wiss. Math.-Natur. Kl. S.-B. II 177 (1969) 203-214.

[5] W. Imrich, Über das schwache kartesische Produkt von Graphen, J. Combin. Theory Ser. B 11 (1971) 1-16. doi:10.1016/0095-8956(71)90008-6

[6] W. Imrich, J. Jerebic and S. Klavžar, The distinguishing number of Cartesian products of complete graphs, European J. Combin. 29 (2008) 922-929. doi:10.1016/j.ejc.2007.11.018

[7] W. Imrich and S. Klavžar, Distinguishing Cartesian powers of graphs, J. Graph Theory 53 (2006) 250-260. doi:10.1002/jgt.20190

[8] W. Imrich, S. Klavžar and V. Trofimov, Distinguishing infinite graphs, Electron. J. Combin. 14 (2007) \#R36.

[9] S. Klavžar and X. Zhu, Cartesian powers of graphs can be distinguished by two labels, European J. Combin. 28 (2007) 303-310.

doi:10.1016/j.ejc.2005.07.001

[10] D.J. Miller, The automorphism group of a product of graphs, Proc. Amer. Math. Soc. 25 (1970) 24-28. doi:10.1090/S0002-9939-1970-0262116-3

[11] D.J. Miller, Weak cartesian product of graphs, Colloq. Math. 21 (1970) 55-74.

[12] A. Russell and R. Sundaram, A note on the asymptotics and computational complexity of graph distinguishability, Electron. J. Combin. 5 (1998) \#R2.

[13] G. Sabidussi, Graph multiplication, Math. Z. 72 (1959/1960) 446-457.

[14] S.M. Smith, T. Tucker and M.E. Watkins, Distinguishability of infinite groups and graphs, Electron. J. Combin. 19 (2012) \#P27.

[15] V.G. Vizing, The Cartesian product of graphs, Vychisl. Sistemy 9 (1963) 30-43, in Russian.

Received 5 August 2015

Revised 7 March 2016

Accepted 7 March 2016 